\title{
Studi Awal Model Panas Bumi Dengan Menggunakan Metode Beda Hingga
}

\author{
Jainal Abidin \\ Universitas Graha Nusantara Padangsidimpuan \\ abidinjainal27@gmail.com
}

\begin{abstract}
ABSTRAK
Sumber daya panas bumi secara umum berasosiasi pada daerah magmatik dan vulkanik sebagai sumber panas dalam sistem panas bumi. Dengan pemanfaatan energi panas bumi sebagai energi alternatif yang ramah lingkungan dan terbarukan yang diharapkan dapat menanggulangi kekurangan energi energi yang dihasilkan dari minyak bumi dan gas. Dengan pemanfaatan energi panas bumi ini menjadi pembangkit listrik tenaga panas bumi untuk menghasilkan energi listrik untuk memenuhi kebutuhan energi listrik yang semakin hari semakin meningkat seiring berkembangnya ilmu pengetahuan dan teknologi. Berdasarkan kandungan potensi panas bumi dapat digambarkan dari parameter-parameter diantaranya faktor kedalaman reservoir, temperatur dan tekanan. Dengan menggunakan metode beda hingga dilakukan analisis secara numerik dan pemograman data dengan menginput temperatur untuk mencari sebaran panas, kedalaman, dan tekanan serta beberapa parameter lainnya akan didapat hasil pengolahan data yaitu estimasi besar potensi panas bumi. Dalam penelitian ini dengan asumsi sebaran panas secara konduksi pada keadaan tetap dalam dua dimensi didapat hasil sebaran panas dengan menginput temperatur awal $230^{\circ} \mathrm{C}$, kemudian akan didapat bentuk dari sebaran panas.
\end{abstract}

Kata kunci: Panas Bumi, Metode Beda Hingga

ABSTRACT

Geothermal resources are generally associated with magmatic and volcanic regions as sources of heat in geothermal systems. With the use of geothermal energy as an alternative energy that is environmentally friendly and renewable which is expected to overcome energy shortages produced from oil and gas. With the use of geothermal energy this is a geothermal power plant to produce electricity to meet the electricity needs that are increasingly increasing with the development of science and technology. Based on the content of geothermal potential can be illustrated from the parameters including reservoir depth, temperature and pressure factors. By using a different method to do numerical analysis and programming data by inputting temperature to find the distribution of heat, depth, and pressure and several other parameters will be obtained from the results of data processing, which is a large estimate of geothermal potential. In this study, assuming conduction heat distribution in a fixed state in two dimensions is obtained by the results of heat distribution by inputting the initial temperature of 2300C, then the form of heat distribution will be obtained.

Keywords: Geothermal, Finite Difference Method

\section{PENDAHULUAN}

Perkembangan ilmu pengetahuan dan teknologi mengakibatkan kebutuhan akan energi meningkat sangat pesat yang mengakibatkan pasokan energi yang berasal dari minyak bumi dan gas tidak mampu dalam mencukupi kebutuhan energi yang tinggi. Solusi untuk mencukupi energi yang dibutuhkan dengan memanfaatkan energi panas bumi yang ramah lingkungan dan terbarukan yang dapat diolah untuk pembangkit listrik tenaga panas bumi. Salah satu sumber daya alam di Indonesia yang dijadikan sebagai energi alternatif adalah panas bumi atau yang lebih sering disebut geothermal. Sistem panas bumi merupakan kandungan energi yang tersimpan dalam bentuk air panas atau uap panas pada kondisi geologi tertentu pada kedalaman beberapa kilometer di dalam 
kerak bumi (Broto, 2011). Sistem panas bumi pada dasarnya representasi dari mekanisme alami yaitu panas ditransfer dari permukaan panas bagian dalam yaitu sumber panas ke permukaan lebih dingin yaitu permukaan disekitar (Singarimbun, 2012). Sebuah anomali suhu dalam formasi bebatuaan sebagai bukti keberadaan panas bumi sebagai cadangan energi (Meng, 1970). Fluida panas bumi berasal dari air permukaan yang berasal dari dalam permukaan bawah batuan melalui celah-celah atau batu permeabel (Putra, 2014). Tanah di sekitar pertukaran panas bumi merupakan media berpori yang terdiri dari bahan padat, air dan gas multifase (Jiao, 2014). Karena air panas lebih ringan dari air dingin, maka air panas akan cenderung bergerak ke atas melalui retakan atau batuan permeabel dan akan muncul permukaan air panas atau geyser.

Hingga saat ini panas bumi merupakan salah satu kekayaan sumber daya alam yang belum banyak dimanfaatkan, namun menjadi sorotan karena manfaat dan efisiensinya. Negaranegara di dunia mulai menggunakan energi panas bumi seiring semakin melonjaknya harga minyak bumi. Energi panas bumi memiliki ketersediaan jangka panjang merupakan energi terbarukan yang efisien di seluruh dunia membuat sumber energi yang efektif untuk pasokan energi berkelanjutan (Cacace, 2010). Berdasarkan IEA (Badan Energi Internasional) memperkirakan bahwa, pemanfaatan pembangkit listrik panas bumi bisa menghasilkan $1.400 \mathrm{TWh}$ per tahun hingga tahun 2050, memberikan kontribusi sekitar 3,5\% dari perkiraan konsumsi listrik di dunia untuk setiap tahunnya (Jiang, 2016). Dari perkiraan IEA tersebut pengembangan energi terbarukan sangatlah membantu pasokan energi. Dalam sistem panas bumi, untuk memprediksi parameter-parameternya menggunakan cara-cara alternatif yang salah satunya adalah melalui metode pemodelan numerik (Putra, 2014).

Perlu diketahui bahwa simulasi numerik pada panas bumi ini difokuskan pada perilaku elemen pada sistem reservoir dan bukan pada struktur termal seluruhnya. Sebaran panas bumi yang akan didapat yaitu sebaran panas secara konduksi pada keadaan dua dimensi. Dengan menggunakan metode beda hingga akan dilakukan diskritisasi pada persamaan Laplace yang didapatkan dari penurunan konduksi panas pada keadaan tetap dua dimensi. Jadi dalam penelitian ini, dilakukan pemodelan sebaran panas secara konduksi pada keadaan tetap dua dimensi dengan menggunakan metode beda hingga.

\section{KAJIAN TEORI}

\section{Konduksi pada Keadaan Tetap Dua Dimensi}

Dari sudut pandang geologi, sumber energi panas bumi berasal dari magma yang berada di dalam bumi. Ia berperan seperti kompor yang menyala. Magma tersebut menghantarkan panas secara konduktif pada batuan sekitarnya. Panas bumi ditransfer melalui konduksi sebanding dengan produk dari perbedaan suhu antara permukaan dan bawah permukaan pada kedalam tertentu dan konduktivitas termal batuan di mana panas lewat. Kuantitas fisik yang relevan untuk fraksi panas ini disebut aliran panas bumi, yang di amati secara langsung di permukaan dengan melakukan pengeboran kedalaman dan mengukur suhu antara permukaan dan kedalaman serta konduktivitas termalnya (Putra, 2014).

Konduksi pada keadaan tetap digunakan pada persamaan differensial orde dua yang solusinya memenuhi persamaan differensialnya dan kondisi 
batasnya dan metode pemisahan variabel digunakan untuk membangun solusi (Jiji, 2009). Konduksi pada keadaan tetap dua dimensi ini bertujuan untuk memprediksi suhu dan tingkat panas dalam medium dan pada batas-batasnya secara numerik dengan menggunakan metode beda hingga (Incropera, 2007). Untuk perpindahan panas secara konduksi merupakan hubungan dasar dari perpindahan panas yang dikemukakan oleh ilmuwan Prancis J.B.J Fourier. Selanjutnya berdasarkan dari hukum kedua Termodinamika yang menyatakan bahwa konduktivitas panas akan mengalir dari suhu yang tinggi ke suhu yang lebih rendah (Purwanto, 2007).

$$
q=-k \frac{\Delta T}{\Delta x}
$$

Untuk perpidahan laju konduksi panas dalam arah $x$ (pada elemen) yaitu $q_{x}$ dapat ditulis:

$$
q_{x}=\left(-k \frac{\partial T}{\partial x}\right) d z
$$

sedangkan konduksi panas pada elemen dikurang dengan laju aliran yang keluar dari elemen sehingga di peroleh:

$$
q_{x}-q_{x+d x}=\frac{\partial}{\partial x}\left(k \frac{\partial T}{\partial x}\right) d x d z
$$

dan untuk arah $z$ laju konduksinya $\left(\mathrm{q}_{\mathrm{z}}\right)$ dapat dicari seperti yang dilakukan pada laju konduksi arah $x\left(q_{x}\right)$, sehingga akan diperoleh:

$$
q_{z}-q_{z+d x}=\frac{\partial}{\partial z}\left(k \frac{\partial T}{\partial z}\right) d x d z
$$

untuk langkah selanjutnya pada persamaan (3) dan (4) dibagi dengan $d x d z$ dan kemudian dilakukan subtitusi ke dalam persamaan kesetimbangan energi akan diperoleh:

$$
\frac{\partial}{\partial \mathrm{x}}\left(k \frac{\partial T}{\partial x}\right)+\frac{\partial}{\partial}\left(k \frac{\partial T}{\partial z}\right)+q=c \rho \frac{\partial T}{\partial \theta}
$$

selanjutnya dilakukan penyederhanaan pada persamaan tersebut, sehingga menjadi:

$$
\frac{\partial^{2} T}{\partial \mathrm{x}^{2}}+\frac{\partial^{2} T}{\partial z^{2}}+\frac{\rho}{k}=\frac{1}{A} \frac{\partial T}{\partial \theta}
$$

dalam dua dimensi konduksi pada keadaan tetap yang mengasumsikan keadaan yang homogen, panas jenis(c) dan kepadatan massanya tidak tergantung suhu dan dianggap seragam, sehingga diperoleh:

$$
\frac{\partial^{2} T}{\partial \mathrm{x}^{2}}+\frac{\partial^{2} T}{\partial z^{2}}=0
$$

\section{Metode Beda Hingga}

Metode beda hingga secara umum adalah metode yang digunakan dalam menyelesaikan permasalahan fisis yang mempunyai bentuk yang teratur, seperti interval dalam satu dimensi, domain kotak dalam dua dimensi dan domain kubik dalam tiga dimensi. Metode beda hingga merupakan pendekatan numerik untuk memecahkan persamaan diferensial (Edwards, 2014). Metode ini dilakukan dengan menggunakan deret Taylor yang diputus pada orde tertentu sesuai dengan masalah yang diselesaikan. Berikut ekspansi dari persamaan deret Taylor (Recktenwald, 2011).

$$
\begin{aligned}
& f(x+\Delta x)=f(x)+\frac{\partial f}{\partial x} \frac{\Delta x}{1 !}+\frac{\partial^{2} f}{\partial x^{2}} \frac{\Delta x^{2}}{2 !}+\frac{\partial^{3} f}{\partial x^{3}} \frac{\Delta x^{2}}{3 !}+\ldots . .+\frac{\partial^{n} f}{\partial x^{n}} \frac{\Delta x^{n}}{n !} \\
& f(x-\Delta x)=f(x)-\frac{\partial f}{\partial x} \frac{\Delta x}{1 !}+\frac{\partial^{2} f}{\partial x^{2}} \frac{\Delta x^{2}}{2 !}-\frac{\partial^{3} f}{\partial x^{3}} \frac{\Delta x^{2}}{3 !}+\ldots . .-\frac{\partial^{n} f}{\partial x^{n}} \frac{\Delta x^{n}}{n !}
\end{aligned}
$$

Dari ekspansi dari persamaan deret Taylor diatas akan didapat tiga persamaan beda hingga yaitu:

Beda maju

$$
\frac{\partial f}{\partial x}=\frac{f(x+\Delta x)-f(x)}{\Delta x}
$$

Beda mundur

$$
\frac{\partial f}{\partial x}=\frac{f(x)-f(x+\Delta x)}{\Delta x}
$$


Beda pusat

$$
\frac{\partial f}{\partial x}=\frac{f(x+\Delta x)-f(x-\Delta x)}{2 \Delta x}
$$

Sedangkan untuk turunan keduanya akan didapat:

$\frac{\partial^{2} f}{\partial x^{2}}=\frac{f(x+\Delta x)-2 f(x)+f(x-\Delta x)}{\Delta x^{2}}$

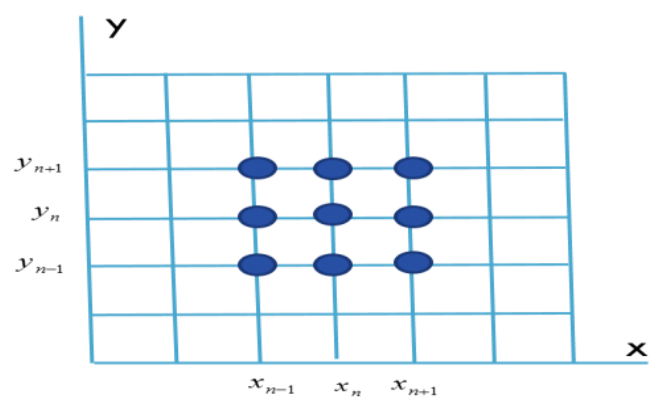

Gambar 1. Grid Sistem

\section{PEMBAHASAN}

Berdasarkan konduksi panas pada dalam dua dimensi sehingga didapat persamaan Laplace dan diselesaikan dengan menggunakan metode beda hingga. Pada tahap ini dilakukan subtitusi dari turunan kedua dari ekspansi deret Taylor ke dalam persamaan Laplace dan kemudian dilakukan distkritisasi untuk menyederhakan persamaan tersebut,

$$
\frac{\partial^{2} T}{\partial \mathrm{x}^{2}}+\frac{\partial^{2} T}{\partial z^{2}}=0
$$

dan untuk turunan keduanya:

$$
\begin{aligned}
\frac{\partial^{2} T}{\partial x^{2}} & =\frac{T_{i+1},{ }_{j}-2 T_{i},{ }_{j}+T_{i-1},_{j}}{\Delta x^{2}} \\
\frac{\partial^{2} T}{\partial z^{2}} & =\frac{T_{i},{ }_{j+1}-2 T_{i},{ }_{j}+T_{i},{ }_{j-1}}{\Delta z^{2}}
\end{aligned}
$$

sehingga dari persamaan diatas (15) dan (16) disubtitusikan ke dalam persamaan Laplace (14) sehingga diperoleh:

$\frac{f\left(x_{i+1}, y_{j}\right)-2 f\left(x_{i}, y_{j}\right)+f\left(x_{i-1}, y_{j}\right)}{h^{2}}+$

$$
\frac{f\left(x_{i}, y_{j+1}\right)-2 f\left(x_{i}, y_{j}\right)+f\left(x_{i}, y_{j-1}\right)}{k^{2}}=0
$$

selanjutnya dilakukan distkritisasi persamaan (17) sehingga akan didapat persamaan yang lebih sederhana yaitu:

$4 T_{i, j}-T_{i+1, j}-T_{i-1, j}-T_{i, j+1}-T_{i, j-1}=0$

Langkah selanjutnya yaitu dengan menyelesaikannya secara numerik yang dibantu oleh penggunaan komputer. Berikut gambar dari diagram alir dari metode penelitian.

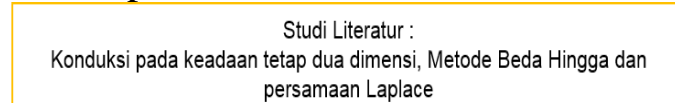
persamaan Laplace

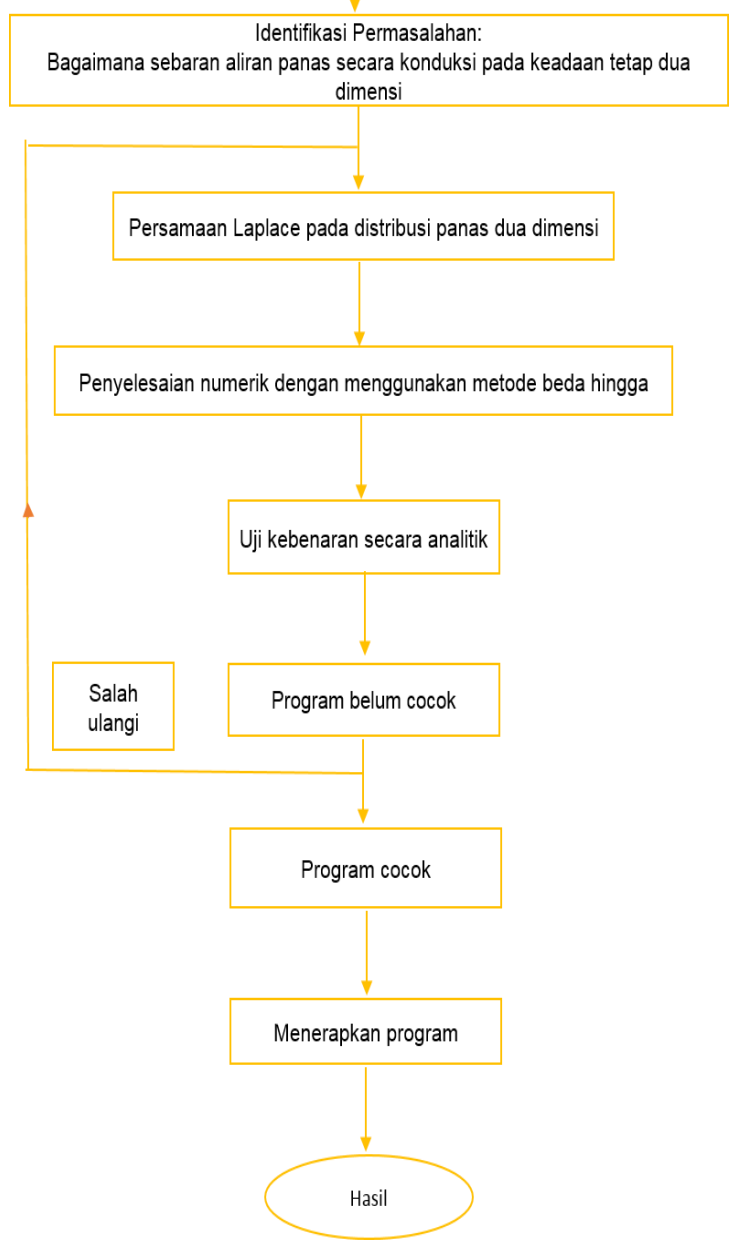


Gambar 2. Diagram Alir Metode Penelitian

Dengan menggunakan bahasa program $\mathrm{C}$ dilakukan pemograman sebaran panas secara konduksi dengan grid $120 \times 120,100 \times 100,50 \times 50,20 \times 20$, dan $10 \times 10$ dengan input temperatur awalnya $230^{\circ} \mathrm{C}$ serta jarak antara grid sama. Berikut gambar asumsi syarat batas dari temperatur yang dilakukan dalam keadaan stabil secara konduksi dalam keadaan tetap dua dimensi.

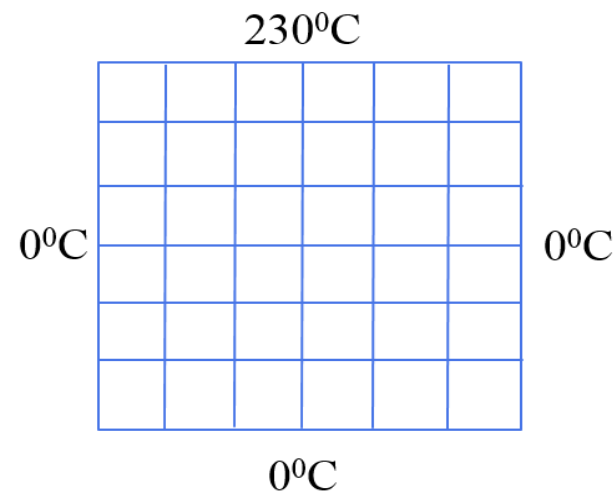

Gambar 3. Syarat Batas Temperatur

Akan didapatkan bentuk sebaran panas yaitu:

Untuk grid 120 x 120

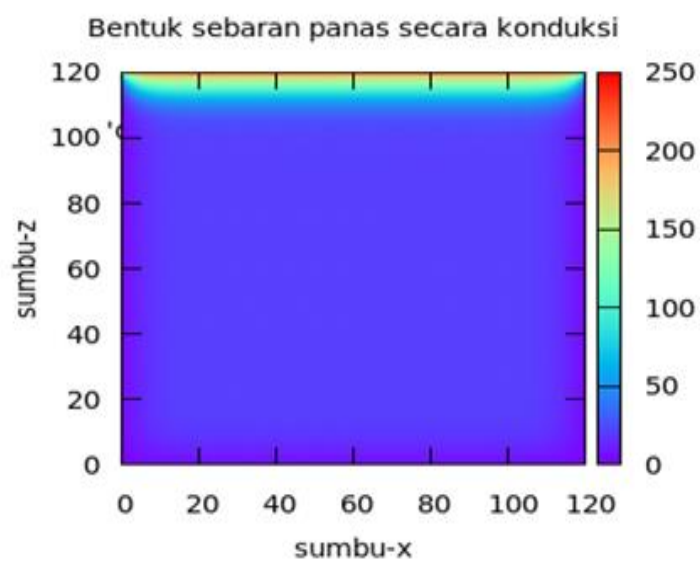

Gambar 4. Hasil Grid 120 x 120

Untuk grid 100 x 100

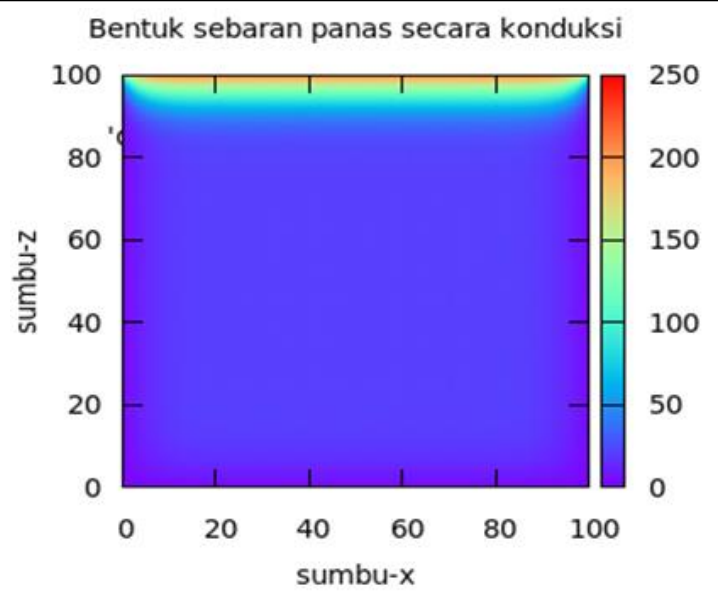

Gambar 5. Hasil Grid 100 x 100 Untuk grid $50 \times 50$

Bentuk sebaran panas secara konduksi

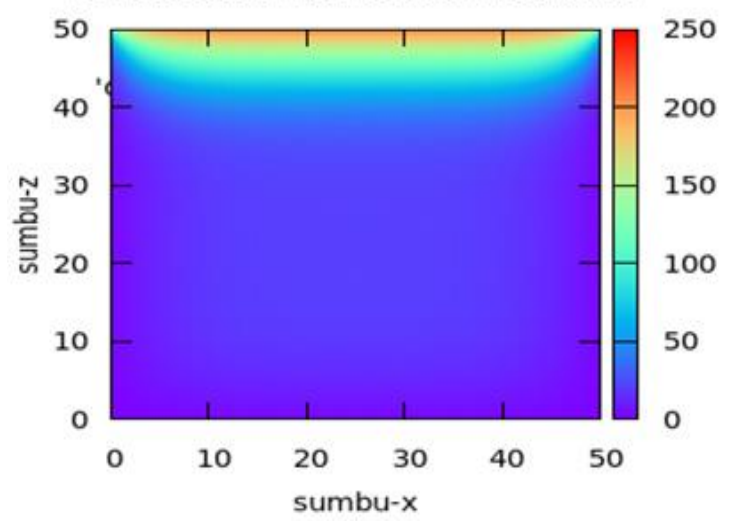

Gambar 6. Hasil Grid 50 x 50

Untuk grid $20 \times 20$

Bentuk sebaran panas secara konduksi

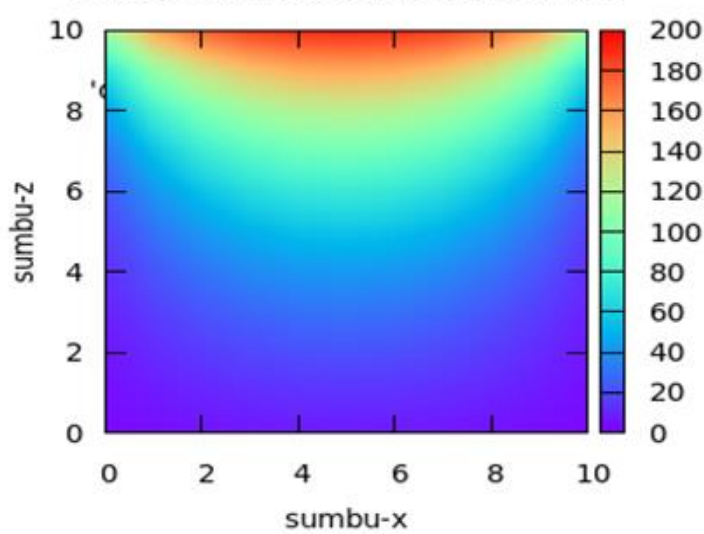

Gamab 7. Hasil Grid 20 x 20

Untuk grid $10 \times 10$ 


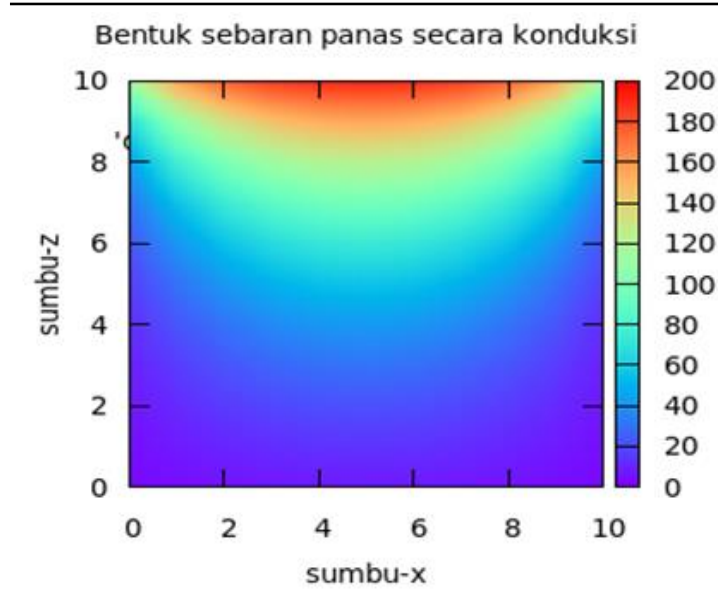

Gambar 8. Hasil Grid 10 x 10

Dari hasil panas di atas dapat di lihat sebaran panas yang didapat secara konduksi pada keadaan tetap dua dimensi, pada grid 120 x 120 sampai $10 \times 10$ dilakukan untuk memperjelaskan sebaran panas yang terjadi.

\section{PENUTUP}

\section{Kesimpulan}

Pemanfaatan sumber energi panas bumi sangat membantu pasokan energi yang dibutuhkan dan enrgi panas bumi adalah energi yang terbarukan dan jangka panjang. Didapatkan bentuk sebaran panas secara konduksi dalam keadaan tetap dua dimensi dengan menggunakan metode beda hingga.

\section{Saran}

Harapan selanjutnya yaitu mencari estimasi potensi energi panas bumi dengan menginput beberapa parameter sebaran panas baik itu faktor kedalaman reservoir, temperatur, massa jenis, konduktivitas dan tekanan.

\section{DAFTAR PUSTAKA}

Broto, S., \& Putranto, T.T. (2011). Aplikasi Metode Geomagnet dalam Eksploitasi Panas Bumi. Teknik - Vol. 32 No. 1.

Cacace, M., Kaiser, B.O., Lewerenz, B., \& Wenderoth, M.S. (2010). Geothermal
Energy in Sedimentary Basins: What We can Learn from Regional Numerical Models. Chemie der Erde 70. Doi: 10.1016/j.chemer.2010.05.017.

Edwards, E., \& Lobaugh, M. (2014). Using Excel to Implement the Finite Diffrence Method for 2-D Heat Transfer in a Mechanical Engineering Technology Course. American Society for Engineering Education.

Incropera, F. P. (2007). Fundamental of Heat and Mass Transfer. United States of America, John Wiley \& Sons.

Jiang, P., Li, X., Xu, R., \& Zhang, F. (2016). Heat Extraction of Novel Underground Well Pattern Systems for Geothermal Energi Exploitation. Renewable Energy 90.

Jiao, Q., \& Zhang, Y. (2014). Modeling and Simulation of Heat and Moisture Transfer of the Geohermal Borehole. Chinese Control and Decision Conference.

Jiji, M.L. (2009). Heat Conduction. New York, Springer.

Meng, C.Y., \& Shaw, P.T. (1970). Study of Heat Conduction Model of Geothermal Energi Reservoirs. Symposium on the Development and Utilization of Geothermal Resources, Vol. 2.

Purwanto, A. (2007). Analisis Data Suhu, Konduktifitas, Dan Aliran Panas Untuk Menafsir Struktur Bawah Permukaan Daerah Air Putih Lebong Utara. Jurnal Gradien Vol. 3 No. 2.

Putra, S.D.H., Fajar, S.j., \& Srigutomo, W. (2014). Numerical Modeling of 2-D Conductive Heat Transfer and Its Application for the Characterization of Geothermal Systems. International Conference on Physics.

Recktenwald, G.W. (2011). Finite Difference Approximations to the 
Heat Equation. Associate Professor, Mechanical Engineering Department Portland State University.

Singarimbun, A., Djamal, M., \& Setyoko, S. (2012). Estimation of Parameters Distribution and Injection Prosess in Geothermal Reservoir. Internasional Journal of Energi and Environment. Isue 6, volume 6 .

\section{RIWAYAT HIDUP PENULIS}

Jainal Abidin, S.Pd., M.Si. Lahir di Padangsidimpuan, 27 Maret 1989. Staf pengajar di Prodi Pendidikan Fisika Fakultas Keguruan dan Ilmu Pendidikan Universitas Graha Nusantara Padangsidimpuan. Studi S1 Pendidikan Fisika STKIP "Tapanuli Selatan" Padangsidimpuan, Padangsidimpuan, lulus tahun 2013. S2 Sains Komputasi Institut Teknologi Bandung, Bandung, lulus tahun 2016. 


\section{THIS PAGE IS INTENTIONALLY LEFT BLANK}

